\title{
APHIDIDAE (INSECTA: HOMOPTERA) PROCEDENTES DE CANTA (LIMA - PERU) ${ }^{1}$
}

VERONICA E. RUBIN DE CELIS

MENANDRO S. ORTIZ

Facultad de Ciencias Biológicas, Universidad Ricardo Palma. Apdo. 138 Lima - Perú

\section{RESUMEN}

Se han identificado las siguientes especies: Acyrthosiphon bidenticola. A. kondoi, Aphis craccivora, A. fabae, A. gossypii, Hyalopterus pruni, Hyperomyzus lactucae, Macrosiphum euphorbiae, M. rosae, Myzus persicae, Rhopalosiphum maidis, R. padi, Sipha flava, Toxoptera aurantii, T. citricidus y Uroleucon erigeronensis. Todas las especies se citan por primera vez para la localidad de Canta.

\section{SUMMARY}

The following species are identified: Acyrthosiphon bidenticola, A. kondoi. Aphis craccivora, A. fabae, A. gossypii, Hyalopterus pruni, Hyperomyzus lactucae, Macrosiphum euphorbiae, M. rosae, Myzus persicae, Rhopalosiphum maidis, R. padi, Siphaflava, Toxoptera aurantii, T citricidus and Uroleucon erigeronensis. All of them are new records for these area (Canta).

\section{INTRODUCCION}

Los áfidos están comprendidos en una familia de homópteros que involucra especies de gran importancia económica, tanto por el daño directo que ocasionan a las plantas cultivadas, de importancia agrícola u ornamental, así como por su daño indirecto, comprendido por la transmisión de virus fitopatógenos, que ocasionan diversas enfermedades en las plantas. Por ello, por múltiples razones, como la de obtener medidas de control eficiente, es preciso determinar las especies provenientes de diversos hospederos así como establecer los registros pertinentes de las localidades estudiadas. El presente trabajo en la localidad de Canta, cumple con tales objetivos.

\section{ANTECEDENTES}

Wille (1952), citó algunas especies de áfidos, como Aphis gossypii y Rhopalosiphum maidis, desde un punto de vista agronómico. Smith (1971a, b) fue quien realmente impulsó los trabajos taxonómicos en el país; registrando especies como Macrosiphum euphorbiae, Myzus persicae y Metopolophium dirhodum.

Ortíz (1972), efectuó un inventario procedentes de la costa central, presentando a Hysteroneura setariae, Tuberolachnus salignus y otras. Más adelante, Ortiz (1973) registró a Rhopalosiphoninus latysiphon, pro- veniente de San Mateo; y en 1974 observó la presencia de un ejemplar macho de Myzus persicae. La importancia de este registro radica en que es el primero de esta naturaleza, dado que los áfidos en el neotrópico presentan partenogenesis telitokia obligatoria.

Valencia y Cárdenas (1973), trabajaron con especies del Valle de Ica y posteriormente, Valencia (1975) estudió áfidos provenientes del Valle del Mantaro.

Ortiz et al. (1981) estudiaron los áfidos de cebada, en las localidades de Huaraz, Huancayo y Lima, relacionándolos con el virus del enanismo amarillo de la cebada (BYDV). Ortiz y Raven (1990) registraron a Cerataphis palmae, Aphis nasturtii y otras especies.

\section{MATERIALES Y METODOS}

Las colecciones se llevaron a cabo en la Provincia de Canta, entre Abril y Agosto de 1991. En dicha localidad predomina el cultivo de plantas de importancia agrícola distribuída en parcelas, las que fueron base de la colección, así como también malezas. Se revisó todos los órganos de las plantas. Se hizo uso de un pincel No. 00 y viales con alcohol $70 \%$. El montaje de los áfidos se hizo en base al método recomendado por Hille Ris Lambers (1950). 


\section{RESULTADOS}

\section{Acyrthosiphon bidenticola Smith}

Cercana a A. bidentis Eastop (Smith et al. 1963), pero se diferencia porque esta presenta el proceso teriainal más largo, cornículos oscuros y un proceso mediano sobre el vértex. Holman (1974) indica que esta es conocida solo en Africa. Se relaciona también con A. malvae (Mosley), pero ésta presenta mayor número de sensorios secundarios.

Se examinaron 13 aladas, 6 ápteras y 7 ninfas (07.viii.91) sobre Bidens pilosa.

\section{Acyrthosiphon kondoi Shinji}

Comúnmente conocido como el «áfido azul de la alfalfa». Cercana a A. pisum (Harris), sin embargo se diferencia por la chaetotaxia de la cauda. Kono y Papp (1977) señalan que se trata de una especie oriental introducida a los Estados Unidos, en donde se comporta como plaga de la alfalfa.

Se examinó un ejemplar alado (14.ix.91) colectado, accidentalmente, sobre Rosa sp.

\section{Aphis craccivora Koch}

Aunque polífaga, tiene preferencia por las Leguminosae (Cermeli, 1970; Blackman \& Eastop, 1985). En el presente trabajo se le ha colectado sobre Gossypium barbadense, nuevo hospedero en el país.

Se han examinado 72 alados, 33 ápteros y 54 ninfas sobre Phaseolus lunatus (02.vii.91, 02.viii.91, 17.ix.91); 3 alados, 2 ápteros y 14 ninfas sobre Medicago sativa (18.v.91); 5 alados, 2 ápteros y 2 ninfas sobre Gossypium barbadense (2.viii.91, 17.ix.91) y 8 alados, 3 ápteros y 8 ninfas sobre Lens sculenta (17.ix.91).

\section{Aphis fabae Scopoli}

Especie de hábitos polífagos (Blackman \& Eastop, 1985). Ampliamente representadaen regiones temperadas del Hemisferio Norte, Sudamérica yAfrica. Vector de más de 30 virus fitopatógenos.

Se examinaron 19 alados, 2 ápteros y 18 ninfas sobre Phaseolus lunatus (18.viii.91); 22 alados sobre Asparragus officinalis (18.viii.91; 15.ix.91).

\section{Aphis gossypii Glover}

Polífaga y plaga de muchas plantas de importancia económica, particularmente sobre el algodonero. Presenta variaciones de tamaño y coloración.

Se examinaron 46 alados, 49 ápteros y 74 ninfas sobre Medicago sativa (18.v.91), 12 alados y 1 áptero sobre Cymbopogon citratus (14.ix.91); 3 alados y 6 ninfas sobre Lens sculenta (2.viii.91); 52 alados, 68 ápteros y 70 ninfas sobre Gossypium barbadense (17.ix.91).

\section{Hyalopterus pruni (Geoffroy)}

Al parecer restringida a gramíneas y particularmente sobre Arundo donax, tal como lo observaron Cárdenas y Valencia (1970). Gómez-Menor (1943) en España la registró sobre ciruelo y melocotonero, entre otros frutales, aspecto que concuerda con lo señalado por Blackman \& Eastop (1985), debido a que estos son hospederos primarios, en aquellas regiones.

Se examinaron 8 alados y 6 ápteros sobre Arundo donax (18.viii.91).

\section{Hyperomyzus lactucae (Linnaeus)}

Conocida en nuestro medio sobre Sonchus oleraceus formando colonia mixta con algunas especies del género Uroleucon $n_{\star}$ Blackman \& Eastop (1985) indican que este hospedero es secundario, en otras regiones. Agregan que es una especie de origen paleártico, ahora ampliamente representada en el mundo. Se examinaron 2 alados, accidentalmente sobre Rosa sp. (14.ix.91).

\section{Macrosiphum euphorbiae (Thomas)}

Registrada sobre una serie de plantas hospederas de importancia económica, como papa, tomate, camote y muchas plantas ornamentales. Se comporta como vector de más de 40 virus fitopatógenos (Blackman \& Eastop, 1985). Al parecer, tiene como origen la parte norte de América; en la actualidad es cosmopolita.

Se examinaron 14 alados, 20 ápteros y 13 ninfas sobre Ipomoea batatas (18.v.91); 25 alados, 20 ápteros y 5 ninfas sobre Phaseolus lunatus (02.viii.91); 17 alados, 20 ápteros y 3 ninfas sobre Rosa sp. (17.viii.91).

\section{Macrosiphum rosae (Linnaeus)}

Ampliamente distribuída sobre rosas cultivadas, alcanzando comportamiento de plaga (Kono y Papp, 1977). Esta especie puede presentarse con coloración verde, rosado o pardo-rojizo, siendo esta última la coloración de los ejemplares colectados en el presente trabajo, procedente de rosas y de otras plantas como hospederos accidentales, debido a la dispersión por la alta población que tuvo.

Se examinaron 21 alados, 68 áptero y 62 ninfas sobre Rosa sp. (18.v.91, 16.vi.91, 06-viii.91, 17.viii.91, 14.ix.91) y otros ejemplares sobre Tropaeolum majus, Ipomoea batatas, Oxalis tuberosus y Pelargonium peltatum como hospederos accidentales. 


\section{Myzus persicae (Sulzer)}

Especie cosmopolita de gran importancia económica, cuya presencia inflige fuertes daños, tanto directos como indirectos. Sobre este último aspecto, existen diversos trabajos que demuestran que se comporta cono vector de una gran cantidad de virosis en diversas plantas (Hille Ris Lambers y Mac Gillivray, 1959; Heinze, 1966). Muy usada en trabajos de laboratorio con fines de estudios fitopatológicos.

Se examinaron 15 alados, 4 ápteros y 18 ninfas sobre Carica papaya (18.viii.91); 20 alados y 3 ápteros sobre Cymbopogon citratus (14.ix.91); 28 alados y 4 ninfas sobre Rosa sp. (18.ix.91).

\section{Rhopalosiphum maidis (Fitch)}

Se hospeda usualmente sobre gramíneas. Al respecto Cermeli (1970) señala que sus colonias se protegen en las hojas nuevas de dichas plantas. Esta especie adquiere mayor importancia por su comportamiento como vector del virus del enanismo amarillo de la cebada (BYDV), tal como lo indicaron Ortiz et. al. (1981)

Se examinaron 57 alados, 25 ápteros y 7 ninfas sobre Zea mays (18.v.91; 14.ix.91; 17.ix.91).

\section{Rhopalosiphum padi (Linnaeus)}

Probablemente de origen paleártico, pero en la actualidad, prácticamente presente en todo el mundo (Blackman \& Eastop, 1985). Registrada en nuestro medio sobre gramíneas (Ortiz et al., 1981). Carrillo y Zúñiga (1974), en Chile la registraron sobre cereales. También, al igual que la especie anterior, es capaz de transmitir el BYDV.

Se examinó sólo 1 áptero sobre gras (11.v.91).

\section{Sipha flava (Forbes)}

Registrada por Wolcott (1928) y Towsend (1939) sobre caña de azúcar, siendo este su hospedero principal, así como otros grases (Kono y Papp, 1977). Blackman \& Eastop (1985) señalan que transmite el virus del mosaico en este hospedero. En esta especie destacan las largas y fuertes setas sobre todo el cuerpo.

Se examinaron 4 alados y 2 ápteros sobre Sorgum halepense (02.viii.91).

\section{Toxoptera aurantii (Boyer de Fonscolombre)}

Se hospeda usualmente sobre árboles y arbustos. Por lo general infesta brotes e inflorescencias. En áreas cultivadas de nuestro medio ha sido observada sobre cítricos y cafeto. Puede formar colonias mixtas con $T$. citricidus (Kirkaldy), especie de color pardo oscuro, en contraste con el color negro de la especie en tratamiento. Entre las bases de los cornículos presenta un área estriada.

Se examinaron 11 alados, 13 ápteros y 33 ninfas sobre Ruta graveolens (23.vi.91, 18.viii.91); 21 alados, 28 ápteros y 39 ninfas sobre Citrus aurantifolia (02.viii.91).

\section{Toxoptera citricidus (Kirkaldy)}

Hallada formando colonias mixtas con $T$. aurantii, la que tiene un mayor rango de hospederos a diferencia de T. citricidus la que se hospeda solo sobre Rutaceae. Holman (1974), indica que está distribuida en áreas ecuatoriales sin estaciones secas, agregando que es bastante conocida en Sudamérica.

Se examinaron 60 alados, 79 ápteros y 205 ninfas sobre Citrus aurantifolia (02. viii. 91).

\section{Uroleucon erigeronensis (Thomas)}

Las especies del género Uroleucon usualmente infestan plantas Compositae (Olive, 1963; Cermeli, 1970. Smith et al. (1963), la relacionan con U. gravicornis, diferenciándola por el número de sensorios secundarios y la longitud del tercer segmento antenal. Según Holman (1974), esta especie es nativa del neártico, llegando hasta la parte tropical de América, siendo asimismo introducida a Europa.

Se examinaron 11 alados, 2 ápteros y 10 ninfas sobre Sonchus oleraceus (14.ix.91).

\section{REFERENCIAS BIBLIOGRAFICAS}

BLACKMAN, R. L. and V. F. EASTOP. 1985. Aphids on the World's crops: An indentification Guide. John Willey \& Sons. N.Y. 466 pp.

CARDENAS, N. y L. VALENCIA. 1970. Nota sobre la verdadera posición taxonómica del pulgón del carrizo (Arundo donax). Univ. Nac. San Luis Gonzaga, Ica, Perú, 1, 59 pp.

CARRILLO, R. y E. ZUÑIGA, 1974. Clave para determinar las especies de áfidos (Homoptera: Aphididae) que se encuentran en los cereales de Chile. Agro Sur 2: 86-87.

CERMELI, M. 1970 Los áfidos de importancia agrícola en Venezuela y algunas observaciones sobre ellos (Homoptera: Aphididae). Maracay, Venezuela, 20: 15-61.

GOMEZ-MENOR,J. 1943. Afidos que viven sobre frutales. Estudio de Fitopatologia Agrícola. Madrid, España. 
HEINZE, K. 1966. Problemas fitopatológicos para la producción de papa en Venezuela. Rev. Agr. Trop. 16: 83-94

HILLE RIS LAMBERS, D. 1950. On Mounting Aphids and other softskinned insects. Ent. Berichten, Amst. 13:55-58

HILLE RIS LAMBERS, D. and E. MACGILLIVRAY. 1959. Scientific names of potatoes infesting aphids. Cant. Ent. Vol 91

HOLMAN J. 1974. Los afidos de Cuba. Inst. Cubano del Libro, La Habana, $304+32$ pl.

KONO, T. and PAPP, Ch. 1977. Handbook of Agricultural Pests: aphids, thrips, mites, snails and slugs. Dept. Food Agr. Div. Plant. Ind. 205 pp.

OLIVE, T. 1963. The Genus Dactynotus Rafinesque in North Caroline (Homoptera: Aphididae). Misc. Public, Ent. Soc. Amer. 4: 1-66.

ORTIZ, M.S. 1972. Notas sobre algunas especies de áfidos en el Perú. XV Convención Nacional de Entomología, Ica. Resúmenes, p. 87.

ORTIZ, M.S. 1973. Rhopalosiphoninus latysophon Davidson, un áfido de sifones peculiares. Rev. Per. Ent. 17: 125-126.

ORTIZ, M.S. 1974. Hallazgo de un macho de Myzus persicae (Sulzer). Rev. Per. Ent. 17: 127-128.

ORTIZ, M.S. y K.G. RAVEN 1990. Nuevos registros de Aphididae (Homoptera). Rev. Per. Ent. 30:
ORTIZ, M.S., A. RODRIGUEZ Y.J.SARMIENTO. 1981. Los áfidos (Homoptera:Aphididae) de la cebada (Hordeum vulgare) en la sierra y costa centrales del Perú. Rev. Per. Ent. 24: 133-136.

SMITH, C. F. 1971a. Survey of aphids on potatoes in Peru with notes on aphids on the order plants. First Report. N.C.S.U.; $11 \mathrm{pp}$.

SMITH, C. F. 1971b. Survey of aphids on potatoes in Peru with notes on aphids on the order plants. Second report, N.C.S.U.; 31 pp.

TOWSEND, C.H.T. 1939, Insectos que atacan al algodonero y a la caña de azùcar en el Perú. Est. Exp. Agric. La Molina. 40 pp.

VALENCIA, L. 1975. Los áfidos (Homoptera; Aphididae) del Valle del Mantaro, plantas hospederas y enemigos naturales. Rev. Per. Ent. 18: 90-97.

VALENCIA, L. y N. CARDENAS. 1973. Los áfidos (Homoptera: Aphididae) del Valle de Ica, sus plantas hospederas y enemigos naturales. Rev. Per. Ent. 16: 6074.

WILLE, J. E. 1952. Entomología Agrícola del Perú. Ministerio de Agricultura, 2da. Ed.; Lima, Perú. 543 pp.

WOLCOTT, G. E. 1928. Los áfidos que afectan a la industria azucarera del Perú. Est. Exp. Agri. La Molina, Perú. Circ. 12: 1-11. 